\title{
The subgenus Migonemyia Galati 1995 (Diptera, Psychodidae, Phlebotominae), with description of a new species Migonemyia vaniae
}

\author{
Eunice A Bianchi Galati $/{ }^{+}$, Mauro Breviglieri Fonseca, Ana Maria Marassá*
}

Departamento de Epidemiologia, Faculdade de Saúde Pública, Universidade de São Paulo, Av. Dr. Arnaldo 715 , 01246-904 São Paulo, SP, Brasil *Secção de Parasitoses Sistêmicas, Instituto Adolpho Lutz, São Paulo, SP, Brasil

The capture of a new species of the subgenus Migonemyia Galati, 1995 (Diptera, Psychodidae, Phlebotominae), Migonemyia vaniae sp. nov. in the Ribeira Valley, state of São Paulo, Brazil, together with the other two species: Mg. migonei (França, 1920) and Mg. rabelloi (Galati \& Gomes, 1992) lead us to review this subgenus. The new species was described and illustrated. The genitalia of the two other species were also illustrated and some genital characteristics (number of setae on the gonocoxite tuft, ejaculatory ducts and pump and ducts/pump ratio; and number of setae on the tergite VIII of the females) considered important to differentiate the three species, including five populations of Mg. migonei (from Northeastern, Southeastern, and Southern Brazilian regions and of Peru) were submitted to variance analyses. The Mg. migonei population of Northeastern Brazilian region showed distinct smaller values $(P<0.05)$ than the other Brazilian populations studied as regarding these characteristics. The capture of both sexes of these three species in sympatry confirms the association between the sexes of $\mathrm{Mg}$. rabelloi, recognised as doubtful when this species was originally described. Identification keys for male and female of the three species are presented.

Key words: review - taxonomy - Migonemyia (Migonemyia) vaniae sp. nov. - Phlebotominae - Psychodidae

A new phlebotomine species of Migonemyia Galati 1995 denominated Migonemyia (Migonemyia) vaniae was captured in a rural area (22J0735878 UTM 7282790), $260 \mathrm{~m}$ above sea level, close to the Atlantic forest reserve on the Serra de Paranapiacaba in the Ribeira Valley, in southern state of São Paulo, Brazil, together with $M g$. migonei and $M g$. rabelloi, between January 2001 and December 2003.

This reserve is located in a transitional area between dense umbriferous submontane forest and mixed umbriferous submontane forest (Veloso et al. 1991), formed of calcareous rock and containing large caves.

The genus Migonemyia was proposed by Galati (1995) within the subtribe Lutzomyiina Abonnenc \& Leger, 1976 and was subdivided by her into two subgenera Migonemyia and Blancasmyia Galati, 1995.

Both sexes of the genus Migonemyia may be characterized as follows: AIII short, smaller or equivalent to half the length of the head; 5th palpomere longer than 3rd; Newstead's spines dispersed on the 3rd palpomere. Males: gonostyle with four spines, presence of the preapical seta, and the inner spine located very close to the apex or beyond the middle, more apically or at same level than the lower external spine; gonocoxite with a basal tuft of setae and basal inner face of gonocoxite without sclerotized longitudinal band. Females: cibarium with

Financial support: Fapesp process no. 00/06811-0

+Corresponding author: egalati@usp.br

Received 8 February 2007

Accepted 2 April 2007 four horizontal posterior teeth and the anterior ones in vertical position arranged in a transversal row, presence of sclerotized area and the posterior bulge; spermathecae tubular or bulbous, and the common sperm duct short or absent.

The subgenus Migonemyia may be distinguished from Blancasmyia in both sexes by the absence of the vetrocervical sensillae. Males: gonostyle with the inner spine located on its apical third. Females: presence of small sclerotized protuberance on tergite IX. Hence, both sexes of Blancasmyia present the ventrocervical sensillae. Males: gonostyle with the inner spine located almost apically. Females: absence of the small sclerotized protuberance on tergite IX.

Two species were then included in the subgenus Migonemyia: Mg. migonei (França, 1920) with wide geographical distribution in South America and $M g$. rabelloi with distribution restricted to the Ribeira Valley, southern state of São Paulo, Brazil (Galati \& Gomes 1992). When this latter species was described the association between the sexes was recognized as uncertain, because although they were both captured in the region of the Ribeira Valley the captures were not made in the same locality. However, a new appraisal of this association became possible with the capture of both genders of these two species together with the new taxon.

Thus, beyond to describe both sexes of the new species and confirming the correct association between the sexes of $M g$. rabelloi, it is also purpose of this paper to present a review of the subgenus.

\section{MATERIALS AND METHODS}

The captures were undertaken with modified automatic light traps (Natal et al. 1991), to which the collection chamber is external and linked to the body of the 
trap by a cotton sleeve, with a plastic casing, $c a .20 \mathrm{~cm}$ long, or with an electric aspirator at a probable resting site with bait for the phlebotomines.

The specimens were measured with a Zeiss ${ }^{\circledR}$ eyepiece calibrated according to a standard Zeiss ${ }^{\circledR}$ scale and drawn with an Olympus ${ }^{\circledR}$ clear chamber. All measurements are given in micrometers. The measurements of paratypes are given in parentheses. The species nomenclature follows Galati $(1995,2003 \mathrm{a})$ and the characters are described in accordance with the same author (2003b). The type material will be deposited in the entomological collections of the Faculdade de Saúde Pública of the Universidade de São Paulo (FSP-USP) and the Centro de Pesquisa Rene Rachou, Fundação Oswaldo Cruz, Belo Horizonte (CPqRR-Fiocruz).

Beyond the type-material of $M g$. vaniae sp. nov., specimens of $M g$. rabelloi and $M g$. migonei deposited in the Epidemiology department (FSP-USP) collections were examined for the following comparison: in the females, the number of setae on the tergite VIII and in males, the number of setae in the gonocoxite tuft; the length of the ejaculatory ducts and the ejaculatory pump and the ratio between these two characters for the three species of the subgenus Migonemyia, covering five populations of $M g$. migonei which occur in different Brazilian regions: one in the South (state of Paraná), two in the Southeast (state of São Paulo: Iporanga municipality and Greater São Paulo metropolitan area), one in the Northeast (state of Ceará), and one in Peru.

For the comparisons of these characteristics, variance analyses were undertaken, the confidence intervals for which were obtained in accordance with Gabriel's method (Sokal \& Hohlf 1981, Rohlf \& Sokal 1981).

Excepting the specimens from Viçosa municipality, state of Ceará, mounted on microscope slides in Canada balsam, all the others, including the others of this same state, after clearing by the method described by Forattini (1973), were mounted in NC medium (Cerqueira 1943). As it is possible that the resins may have had some effect on the length of the ejaculatory ducts and the ejaculatory pump, the specimens of the Brazilian Northeast region were divided into two groups for the variance analyses.

Further, the papilla on the antennomere V (AV) was examined in both sexes.

The geographical distribution presented for $M g$. migonei was based on the data base of the Cipa Group (1997) and complemented for some areas: Brazil: Rondônia (Gil et al. 2003), Mato Grosso do Sul (Martins et al. 1978), Rio Grande do Norte (Ximenes et al. 2000), Alagoas (Saraiva et al. 2006); Colombia: La Guajira (Barreto et al. 2006); Peru: Pasco (Cáceres et al. 2000); Paraguay: Amambay Guaira, Itapuá, Misiones (Salomón et al. 2003).

The following specimens of $M g$. migonei and $M g$. rabelloi were examined:

Mg. migonei. BRAZIL, state of São Paulo: Iporanga municipality, Bairro Serra, A Gurgel's small farm $130^{\text {त }}$ 11 ㅇ 2002, 2003; JD Andrade's small farm $20^{\star} 8$ 우 2001, 2002, 2003; Parque Estadual Turístico do Alto Ribeira (PETAR) 13 q 2001, 2002, EAB Galati, AM Marassá,
RM Gonçalves-Andrade and A Galati col.; Great São Paulo metropolitan area (GSP): Cotia municipality, Bairro Capuava 10 오 10 우 2005, MB Fonseca, DA Silva and VL Berndt col.; São Paulo municipality, Bairro Jaraguá 10 đ 3 q 2001, BJ Dicezare col.; state of Paraná: Lon-drina municipality, Godoy farm $10^{\star} 1975$, AC Gomes col.; Jussara municipality, CMMP farm $10^{\text {† }} 1988$, U Teodoro col.; Ponta Grossa municipality, Vila Velha park 1 o 2006, MF Rosa-Cruz col.; Santa Mariana municipal-

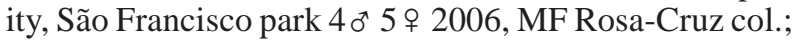
Ribeirão Claro municipality, São Sebastião small farm (cave) 5 o 2006; idem (pigpen) 1 o 2006, Massafera R col.; state of Ceará: 12 đ 47 + 1999 , Funasa-Corse team col.; Viçosa municipality 13 ơ, 1954, Deane col.; state of Amapá: Teresinha municipality 1 \% 1959, Dauer et al. col.; PERU, Pasco Department: Oxapampa province, Villa Rica District 1 o 1997, AG Cáceres col.; Junín Department: Chanchamayo province, San Luis district $10^{\text {t }}$ 2 \% 2001, AG Cáceres col.; Cusco Department: La Convención province, Quelouno district $10^{\text {† }} 2$ ㅇ 1999 , AG Cáceres col.; Puno Department: Sandia Province, San Juan de Oro district 11 o 4 \% 2002, AG Cáceres col.; VENEZUELA, Estado Cojedes: 1 o 1981, Elio col.

Mg. rabelloi. BRAZIL, state of São Paulo: Iguape municipality, Palmeira small farm (forest) 2 ㅇ (holotype and paratype) 1982; Pedro de Toledo municipality, Bairro Araçatuba $10^{\star}$ (paratype) 1974; Cananéia municipality, district of Itapitangui $10^{\top}$ (paratype) 1980; Iporanga municipality, Bairro Serra, A Gurgel's small farm (chicken house) $20^{\star} 1$ क 2003; idem (pigpen) $3 \sigma^{\star} 1$ क 2003; idem (banana tree in middle of pasture) $10^{\top} 2003$; idem (forest) 2 ㅇ 2003, EAB Galati, MB Fonseca and JR Andrade col.

\section{RESULTS}

\section{Description of Migonemyia vaniae sp. nov.} (Figs 1-28, 31, 33, 34)

Holotype (male) - Total body length 2460 (2531 \pm $118 ; n=12$ ). Insect predominantly pale brown, with the head, pronotum, and mesonotum darker brown.

Head (Fig. 1) - Length $330(335 \pm 15 ; \mathrm{n}=12)$; width $330(351 \pm 22 ; \mathrm{n}=12)$. Eye: length $218(214 \pm 13 ; \mathrm{n}=$ $12)$; width $130(123 \pm 6 ; n=12)$ (frontal view). Interocular distance $93(99 \pm 3 ; \mathrm{n}=12)$. Interocular suture separated from antennal suture. Clypeus length 95 (98 $\pm 6 ; \mathrm{n}=12)$. Antennomere lengths: AIII $180(172 \pm$ $8 ; \mathrm{n}=12)$, AIV $83(82 \pm 5 ; \mathrm{n}=12)$, AV $78(79 \pm 4 ; \mathrm{n}=$ 12), AXV $50(53 \pm 1 ; \mathrm{n}=10)$, and AXVI $45(48 \pm 2 ; \mathrm{n}=$ 10). AIII/head length ratio: 0.55:1.0 (0.51 $\pm 0.02: 1.0 ; n$ = 12). Antennal formula AIII - AXV 2, XVI 0 (Figs 310); ascoids simple and long, their apices on AIV go beyond the apex of the segment (Fig. 3); papilla present on AV (Fig. 4); presence of papillae on AXIII. Length of the palpomeres: I $30(31 \pm 3 ; \mathrm{n}=12)$, II $100(103 \pm 8 ; \mathrm{n}=$ 12), III $115(123 \pm 10 ; \mathrm{n}=12)$, IV $113(111 \pm 11 ; \mathrm{n}=$ 12), V $335(322 \pm 21 ; \mathrm{n}=12)$. Palpal formula: 1.2.4.3.5 (1.2.4.3.5; $\mathrm{n}=8 ; 1.4 .2 .3 .5 ; \mathrm{n}=2 ; 1$. 2. (3.4).5; $\mathrm{n}=1 ; 1$. (2.4). 3. $5 ; \mathrm{n}=1$ ); Newstead's spines grouped in the middle of palpomere III, being in number 0 or $2(0,1,2$; $\mathrm{n}=12$ ) on palpomere II (Fig. 21). Labroepipharynx 183 $(185 \pm 13 ; n=12)$ long. Labial sutures united. 


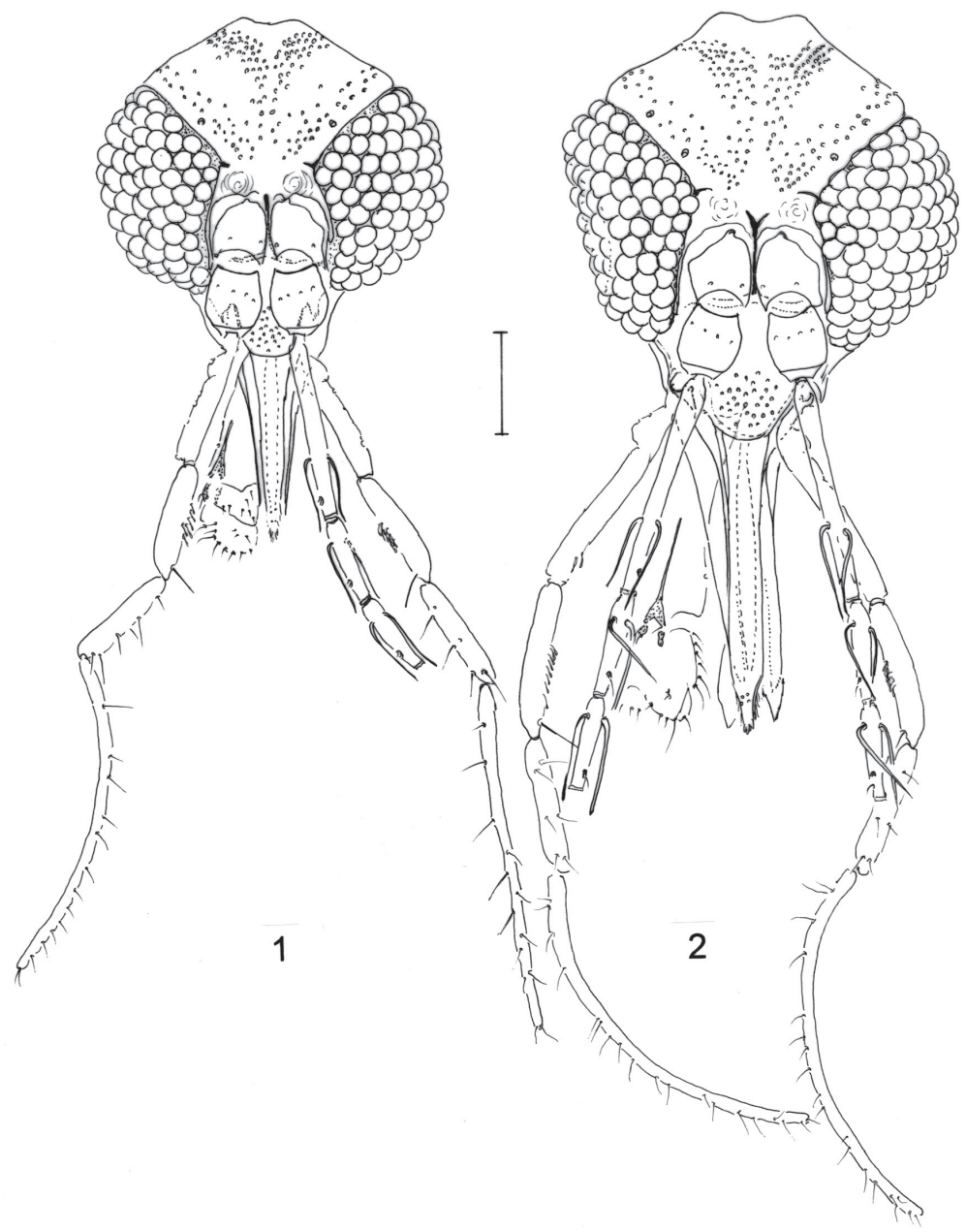

Figs 1-2: Migonemyia vaniae sp. nov. head (holotype male and allotype), frontal view. 1: female; 2 : male. Bar $=100 \mu \mathrm{m}$.

Cervix - ventrocervical sensillae absent.

Thorax - Length $550(550 \pm 35 ; \mathrm{n}=12)$; mesonotum length $500(513 \pm 37 ; \mathrm{n}=12)$. Pleura with 2 proepimeral setae $(2-6 ; \mathrm{n}=12)$ and 10,11 upper anepisternal setae $(6-16 ; \mathrm{n}=12)$. Setae present on the anterior katepisternum margin. Suture between katepimeron and metepisternum absent. Wing (Fig. 24): length 1630 (1675 87; $\mathrm{n}=12)$, width $500(523 \pm 28 ; \mathrm{n}=12)$. Length of vein sections: alpha $470(485 \pm 48 ; \mathrm{n}=12)$, beta $180(177 \pm 20 ; \mathrm{n}=12)$, gamma $200(220 \pm 28 ; \mathrm{n}=12)$, delta $230(218 \pm 35 ; \mathrm{n}=12)$, pi $110(108 \pm 21 ; \mathrm{n}=12)$, $\mathrm{R}_{5} 1040(1118 \pm 66 ; \mathrm{n}=12)$. Length of femora, tibiae, basitarsi, and tarsi II+III+IV+V: foreleg $550(565 \pm 54$; $\mathrm{n}=6), 550(562 \pm 40 ; \mathrm{n}=5), 310(320 \pm 17 ; \mathrm{n}=5), 480$ $(484 \pm 17 ; \mathrm{n}=5) ;$ midleg $580(605 \pm 27 ; \mathrm{n}=6), 685$ $(720 \pm 37 ; n=6), 390(416 \pm 19 ; n=6), 540(570 \pm 20$; $\mathrm{n}=6)$; hindleg $640(651 \pm 39 ; \mathrm{n}=8), 850(890 \pm 68 ; \mathrm{n}$ =7), $475(501 \pm 27 ; \mathrm{n}=7), 605(634 \pm 29 ; \mathrm{n}=7)$.

Abdomen - $1250(1316 \pm 91 ; \mathrm{n}=12)$ long. Tergites III-VII with conspicuous tergal papillae. Terminalia (Fig. 34): gonostyle $115(114 \pm 6 ; n=21)$ long, with 4 major spines; the spines having the following disposition: one apical, the upper external on the 3rd apical part of the structure, the lower external and the internal one beyond the middle of the structure, at the same level. Gonocoxite 215 long $\times 63$ wide $(220 \pm 10 \times 70 \pm 7 ; \mathrm{n}=21)$ with a basal tuft of 8 thin and short (varying from 5 to $10 ; 8 \pm$ $1.0 ; \mathrm{n}=21$ ) setae. Paramere simple, digitiform and slightly convex; dorsal margin length $128(130 \pm 6 ; n=$ $21)$ and ventral margin length $165(164 \pm 12 ; \mathrm{n}=21)$ with setae on the apical half. Conical aedeagus, dorsal margin length $115(103 \pm 12 ; \mathrm{n}=21)$ and ventral margin length $78(74 \pm 6 ; n=21)$. Lateral lobe length 215 (222 $\pm 9 ; n=21)$; width $18(20 \pm 1 ; n=21)$. Genital pump: $143(150 \pm 10 ; n=21)$ long; piston length $118(126 \pm$ $10 ; n=21)$; pavilion width $43(39 \pm 3 ; n=21)$; chamber width $23(25 \pm 3 ; \mathrm{n}=21)$; genital filaments length 642 $(655 \pm 43 ; n=21)$ or $4.49(4.38 \pm 0.3 ; n=21)$ times the length of genital pump. Tip of genital filaments simple (Fig. 33). Cercus $150(150 \pm 10 ; n=21)$ long.

Allotype (female) - Total body length ca. 2697 (2550 $\pm 143 \mathrm{n}=5$ ). General coloration as that of the male.

Head (Fig. 2) - Length 415 (387 $\pm 25 ; \mathrm{n}=5)$; width 


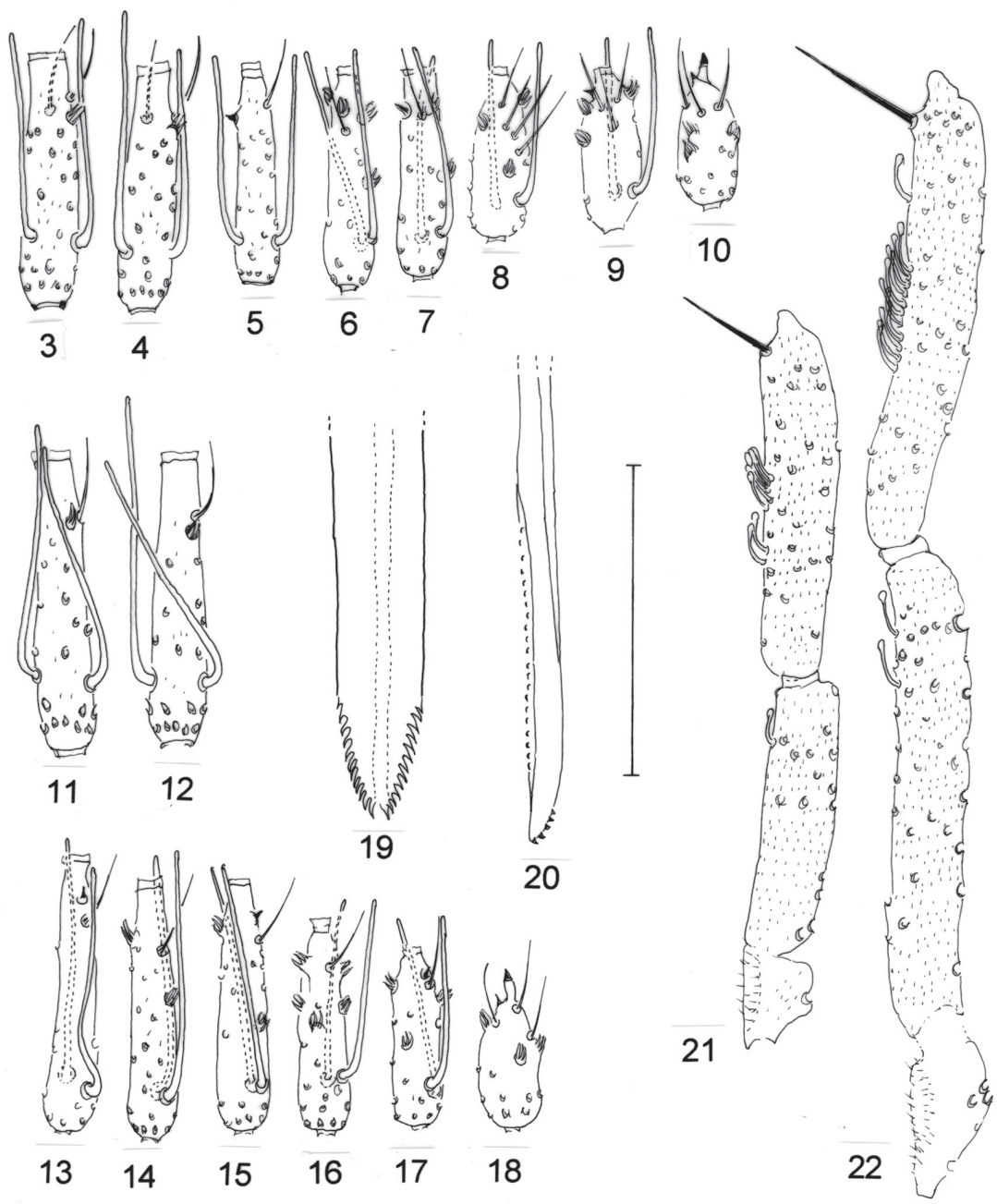

Figs 3-22: Migonemyia vaniae sp. nov. 3-10, 21 (holotype male); 3-10: antennomeres IV, V, XI-XVI, respectively; 21: palpomeres I, II and III; 11-20, 22 (allotype); 11-18: antennomeres IV, V, XI-XVI, respectively; 19: hypopharynx; 20: lacinia; 22: palpomeres I, II and III. Bar $=100 \mu \mathrm{m}$.

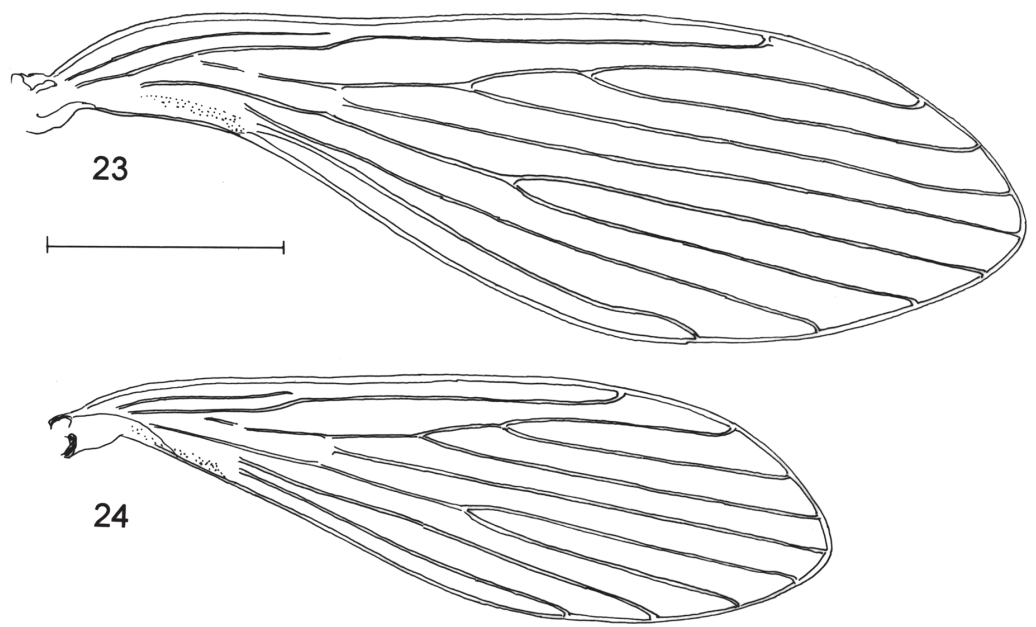

Figs 23-24: wings (allotype and holotype male). Migonemyia vaniae sp. nov. 23: female; 24: male. Bar $=500 \mu \mathrm{m}$. 
$380(366 \pm 18 ; \mathrm{n}=5)$. Eye: length $238(221 \pm 12 ; \mathrm{n}=$ 5); width $138(130 \pm 17 ; n=5)$ (frontal view). Interocular suture separated from antennal suture. Interocular distance $110(106 \pm 11 ; \mathrm{n}=5)$. Clypeus $133(127 \pm 10 ; \mathrm{n}=$ 5) long. Antennomeres: AIII $220(193 \pm 10 ; n=4)$, AIV $100(89 \pm 1 ; \mathrm{n}=4)$, AV $95(88 \pm 0 ; \mathrm{n}=4)$, AXV 58 $(54 \pm 1 ; \mathrm{n}=3)$, and AXVI $50(49 \pm 5 ; \mathrm{n}=3)$. AIII/head length ratio: 0.53:1.0 $(0.51 \pm 0.02: 1.0 ; \mathrm{n}=4)$. Antennal formula AIII - AXV 2, XVI 0 (Figs 11-18); ascoids simple, their apices on AIV go beyond the segment apex (Fig. 11); papilla present on AV (Fig. 12). Palpomere lengths: I $40(41 \pm 5 ; n=5)$, II $158(138 \pm 9 ; n=5)$, III $150(144 \pm 8 ; \mathrm{n}=5)$, IV $125(129 \pm 9 ; \mathrm{n}=5), \mathrm{V} 400$ $(391 \pm 35 ; \mathrm{n}=5)$. Palpal formula: 1.4.3.2.5 or 1.4. (2.3).5; $\mathrm{n}=1$ or 1.4.2.3.5; $\mathrm{n}=4$ ). Newstead's spines distributed in the middle of palpomere III and 1-2 $(0-2 ; n=5)$ near the top of palpomere II (Fig. 22).
Labroepipharynx $283(261 \pm 16 ; \mathrm{n}=5)$ long. Cibarium (Fig. 25) with anterior teeth situated in one developed transversal row; 4 posterior (horizontal) teeth, many lateral greatly reduced teeth, pigment patch and posterior bulge well developed; arch complete. Pharynx (Fig. 25) not armed. Hypopharynx (Fig. 19) with well 12-13 delineated apicolateral teeth. Maxilla: lacinia with 4-5 external teeth disposed in a longitudinal row with about 22 internal teeth (Fig. 20). Labial sutures united.

Cervix - Ventrocervical sensillae absent.

Thorax - Length $720(637 \pm 69 ; \mathrm{n}=5)$; mesonotum $700(597 \pm 60 ; n=5)$ long. Pleurae with 4, $5(1-5 \mathrm{n}=$ 5) proepimeral setae, $13,14(9-17 ; n=5)$ upper anepisternal setae. Setae present on the anterior katepisternum margin. Suture between katepimeron and metepisternum absent. Wing (Fig. 23): length 2060

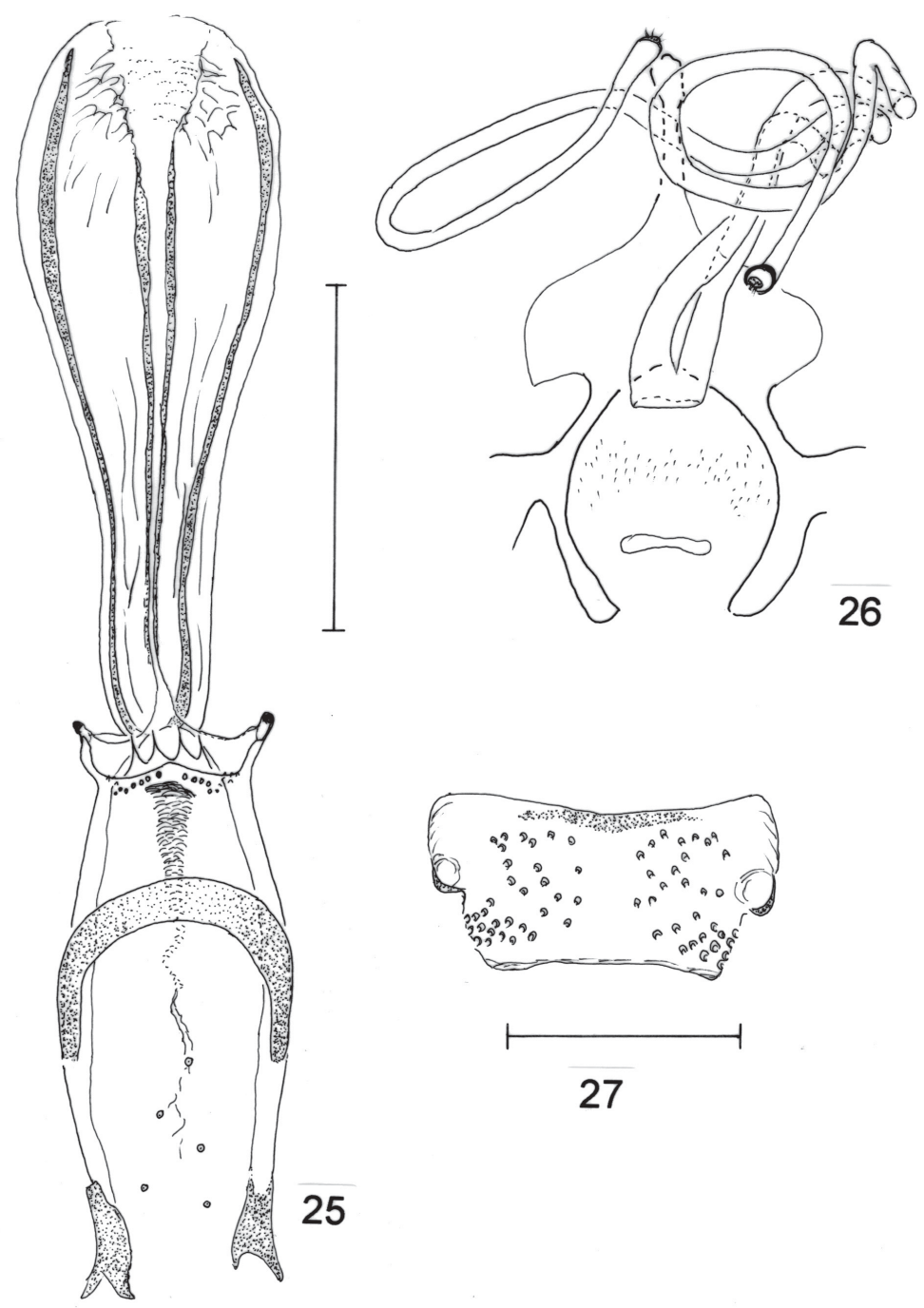

Figs 25-27: Migonemyia vaniae sp. nov. (allotype female ). 25: cibarium and pharynx; 26: genital fork and spermathecae; 27: tergite IX with sclerotized protuberance, dorsal view. $\mathrm{Bar}=100 \mu \mathrm{m}$. 
$(2008 \pm 176 ; \mathrm{n}=5)$ and width $670(620 \pm 73 ; \mathrm{n}=5)$. Length of vein sections: alpha $710(648 \pm 69 ; \mathrm{n}=5)$, beta $240(200 \pm 12 ; \mathrm{n}=5)$, gamma $260(255 \pm 43 ; \mathrm{n}=$ 5), delta $360(336 \pm 42 ; n=5)$, pi $130(130 \pm 20 ; n=5)$, R5 $1440(1382 \pm 172 ; n=5$. Length of femora, tibiae, basitarsi, and tarsi II+III+IV+V: foreleg $720(630 \pm 30$; $\mathrm{n}=3) ; 700(637 \pm 47 ; \mathrm{n}=3) ; 410(347 \pm 35 ; \mathrm{n}=3) ; 590$ (542 23; $\mathrm{n}=3)$; midleg $750(650 \pm 30 ; \mathrm{n}=3) ; 930$ (793 $\pm 67 ; \mathrm{n}=3), 520(453 \pm 15 ; \mathrm{n}=3) ; 640(587 \pm 50 ; \mathrm{n}=$ 3); hindleg $830(710 \pm 36 ; n=3) ; 1110(980 \pm 66 ; n=3)$, $600(550 \pm 27 ; n=3) ; 710(670 \pm 37 ; n=3)$.

Abdomen - Length $1430(1396 \pm 57 ; \mathrm{n}=5)$. Tergite VIII with $1,2(0-3 ; n=5)$ setae. Tergite IX with sclerotized protuberance (Figs 27, 28). Spermathecae (Figs 26, 31) tubular, with no clear transition to the common sperm ducts, measuring $7.4(7.9 \pm 2.1 ; n=5)$ at maximum width; terminal knob highly sclerotized and sessile; individual sperm ducts smooth, 397 (385.4 $\pm 26.5 ; \mathrm{n}=5)$ long; narrowing gradually from their base to the spermathecae, the basal and apical width being $10(9.2 \pm 1.0 ; \mathrm{n}=5)$ and 5.0 $(4.9 \pm .02 ; \mathrm{n}=5)$, respectively; common sperm duct smooth and vestigial. Cercus $132(132 \pm 8 ; \mathrm{n}=5)$ long.

Type-material - Holotype $\sigma^{\top}$ : BRAZIL, state of São Paulo, Iporanga municipality, Bairro Serra, A Gurgel's small farm (chicken-house) 21-22 Mar 2003. Allotype idem 08-09 Dec 2003 (FSP-USP); 21 o 5 क Paratypes: idem $120^{\star} 3$ + 18-19, 22-23 Oct 2003, 06-07, 08-09, 09-10, 10-11, 11-12 Dec 2003 (2 o 1 \% CPqRR-Fiocruz; $100^{\star} 2$ 우 (FSP-USP); idem (pig-pen) $20^{\text {t }} 16-17$ Nov 2003, 7-8 Dec 2003; idem (domicile-veranda) 1 o 2324 May 2003; idem (forest) $3 o^{\star} 1$ ㅇ 12-13, 13-14 Nov, 6-7 Dec 2003, 8-9 Dec 2003 (FSP-USP); idem (pas-

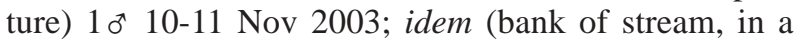
hole between roots used as shelter by a bitch for her litter) $10^{\star} 19$ Nov 2003; idem: Dona. Donária's small farm (peridomicile) 10 12-13 Dec 2003 (FSP-USP) and idem JR Andrade's small farm (pig-pen) $10^{\top} 10-11$ Dec 2003 (FSP-USP). The captures were made by EAB Galati, MB Fonseca, and JR Andrade with modified automatic light traps, except for that in the shelter of the dogs which was undertaken with an aspirator.

Etymology - The name of the new species Migonemyia vaniae derives from that of our colleague Vânia Lúcia Brandão Nunes whom we thus wish to honor in recognition of her dedication to the study of the phlebotomines, leishmaniases, and trypanosomatides of the state of Mato Grosso do Sul.

Migonemyia (Migonemyia) migonei (França, 1920)

Phlebotomus Migonei França, 1920. Holotype ơ: Asunción, Paraguay.

Phlebotomus migonei: Theodor 1932 ( क description and $\sigma^{\top}$ redescription from Argentinean specimens); Barretto 1947 (complete geographical distribution with respective references).

Lutzomyia migonei: Theodor 1948, 1965 (classifications); Barretto 1962 (classification); Martins, Williams, Falcão 1978 (classification and geographical dis- tribution); Young 1979 and Young and Duncan 1994 ( $\sigma^{\star}$ ㅇ redescription, identification keys, and geographical distribution); Aguiar and Medeiros 2003 (Brazilian geographical distribution and habitats); Cipa Group 1997 (geographical distribution, first reference to the species by country, and synonyms).

Sergentomyia migonei: Barretto, 1955 (classification).

Lutzomyia (Coromyia) migonei: Forattini 1971 (classification); Forattini 1973 ( $0^{7}$ o redescription; identification keys).

Migonemyia (Migonemyia) migonei: Galati 1995 (classification); Galati 2003a (classification) Galati 2003b (identification keys and distribution).

Syn. Phlebotomus araozi Paterson \& Shannon, 1926 (Dyar 1929).

Phlebotomus rangeli Nuñez-Tovar, 1924 (Dyar \& Nuñez-Tovar 1926).

Geographical distribution - PARAGUAY (Asunción: type-locality): Alto Paraná, Amambay, Caaguazu, Caazapá, Central, Chaco, Guaira, Itapuá, Misiones, San Pedro. ARGENTINA: Catamarca, Formosa, Jujuy, Misiones, Salta, Santiago del Estero. BOLIVIA: La Paz; BRAZIL: Central-Western Region - Mato Grosso do Sul, Mato Grosso; Northern Region - Acre, Amazonas, Amapá, Pará, Rondônia; Northeastern Region - Alagoas, Bahia, Ceará, Maranhão, Paraíba, Pernambuco, Rio Grande do Norte; Southeastern Region - Espírito Santo, Minas Gerais, Rio de Janeiro, São Paulo; Southern Region - Paraná, Rio Grande do Sul, Santa Catarina; PERU: Madre de Dios, Puno, Pasco, Junín, Cusco; COLÔMBIA: La Guajira, Magdalena; TRINIDAD: Trinidad and Tobago VENEZUELA: Apure, Aragua, Barinas, Carabobo, Cojedes, Distrito Federal, Fálcon, Lara, Mérida, Miranda, Portuguesa, Sucre, Tachira, Trujillo, Yaracuy, Zulia.

Migonemyia (Migonemyia) rabelloi (Galati \& Gomes, 1992)

Lutzomyia rabelloi Galati \& Gomes, 1992 (Holotype ๆ: Iguape municipality, state of São Paulo, Brazil) and probable males; Young \& Duncan, 1994 (reproduction of figures from Galati \& Gomes 1992 and geographical distribution); Cipa Group 1997 (geographical distribution).

Migonemyia (Migonemyia) rabelloi: Galati 2003a (classification) Galati 2003b (identification keys and geographical distribution).

Geographical distribution - BRAZIL: state of São Paulo. The knowledge of this species up to now is limited to the Ribeira Valley region in the following municipalities: Cananéia, Iguape, Iporanga, and Pedro de Toledo.

The results of the variance analyses undertaken to compare the male characteristics: lengths of the ejaculatory pump and duct and the ratio between these two structures are presented in Table I and the number of the setae in the gonocoxite tuft in Table II. The only character for the females, number of setae on the tergite VIII (Table III).

The papilla on the 5th antennomere (AV) is present in both sexes of $M g$. vaniae, sp. nov. and in the $M g$. 
TABLE I

Average with their respective confidence intervals of ejaculatory duct length, ejaculatory pump, and the ratio between the lengths of ejaculatory ducts/ejaculatory pump for Migonemyia vaniae sp. nov., $\mathrm{Mg}$. rabelloi, and six populations of $\mathrm{Mg}$. migonei

\begin{tabular}{lcccr}
\hline $\begin{array}{l}\text { Characteristics/species } \\
\text { (populations) }\end{array}$ & $\mathrm{N}$ & $\begin{array}{c}\text { Ejaculatory duct } \\
\text { saverage (CI) }\end{array}$ & $\begin{array}{c}\text { Ejaculatory pump } \\
\text { average (CI) }\end{array}$ & $\begin{array}{c}\text { Ducts/pump ratio } \\
\text { average (CI) }\end{array}$ \\
\hline Mg. vaniae sp. n. $_{\text {Mg. rabelloi }}$ & 22 & $654.4(637.7-671.1)$ & $149.4(145.9-153.0)$ & $4.39(4.26-4.51)$ \\
Mg. migonei & 8 & $382.9(355.2-410.5)$ & $141.9(136.0-147.8)$ & $2.71(2.50-2.92)$ \\
Mg. migonei $^{b}$ & 12 & $546.7(524.1-569.3)$ & $122.3(117.4-127.1)$ & $4.47(4.30-4.64)$ \\
Mg. migonei & 12 & $557.4(534.8-580.0)$ & $121.7(116.9-126.5)$ & $4.58(4.41-4.75)$ \\
Mg. migonei $^{d}$ & 12 & $549.1(526.5-572.4)$ & $122.9(118.1-127.7)$ & $4.47(4.30-4.64)$ \\
Mg. migonei & 12 & $443.2(420.7-465.8)$ & $116.4(111.6-121.2)$ & $3.82(3.65-3.99)$ \\
Mg. migoneif & 12 & $434.2(411.6-456.8)$ & $113.8(109.0-118.6)$ & $3.81(3.66-3.98)$ \\
\hline
\end{tabular}

Mg. migonei populations. $a$ : Iporanga municipality (Brazilian Southeast region); $b$ : Greater São Paulo metropolitan area (Brazilian Southeast region); $c$ : state of Paraná (Brazilian South region); $d$ : state of Ceará (Brazilian Northeast region); $e$ : Viçosa municipality, state of Ceará (Brazilian Northeast region); $f$ : Peru; CI: confidence interval $(\alpha=0.05)$.

\section{TABLE II}

Number of setae on the gonocoxite tuft of Migonemyia vaniae sp. nov., Mg. rabelloi, and five populations of Mg. migonei

\begin{tabular}{lcccc}
\hline Species (populations) & $\mathrm{N}$ & $\begin{array}{c}\text { Interval } \\
\text { observed }\end{array}$ & Average & CI \\
\hline Mg. vaniae sp. nov. $^{2}$ & 22 & $5-10$ & 7.8 & $7.4-8.3$ \\
Mg. rabelloi & 8 & $11-15$ & 12.4 & $11.6-13.2$ \\
Mg. migonei & 15 & $6-8$ & 6.2 & $5.6-6.8$ \\
Mg. migonei $^{b}$ & 20 & $5-8$ & 6.0 & $5.5-6.5$ \\
${\text { Mg. } \text { migonei }^{c}}^{\text {Mg. } \text { migonei }^{d}}$ & 12 & $5-8$ & 6.5 & $5.9-7.1$ \\
Mg. migonei $^{e}$ & 25 & $2-7$ & 4.6 & $4.1-5.0$ \\
\hline
\end{tabular}

Mg. migonei populations. a: Iporanga municipality (Brazilian Southeast region); $b$ : Greater São Paulo metropolitan area (Brazilian Southeast region); $c$ : state of Paraná (Brazilian South region); $d$ : state of Ceará (Brazilian Northeast region); $e$ : Peru; CI: confidence interval $(\alpha=0.05)$.

\section{TABLE III}

Number of setae on the female tergite VIII of Migonemyia vaniae sp. nov., $M g$. rabelloi, and five populations of Mg. migonei

\begin{tabular}{lrcrc}
\hline Species (populations) & $\mathrm{N}$ & $\begin{array}{c}\text { Interval } \\
\text { observed }\end{array}$ & Average & CI \\
\hline Mg. vaniae sp. nov. & 6 & $0-2$ & 1.0 & $-1.4-3.4$ \\
Mg. rabelloi & 6 & $0-4$ & 3.2 & $0.8-5.6$ \\
Mg. migonei $^{a}$ & 32 & $9-22$ & 14.1 & $13.0-15.1$ \\
Mg. migonei & $b$ & $9-19$ & 12.8 & $11.2-14.5$ \\
Mg. migonei $^{c}$ & 5 & $11-16$ & 13.4 & $10.8-16.0$ \\
Mg. migonei $^{d}$ & 47 & $5-13$ & 8.7 & $7.8-9.6$ \\
Mg. migonei $^{e}$ & 8 & $9-16$ & 12.4 & $10.3-14.5$ \\
\hline
\end{tabular}

Mg. migonei populations. a: Iporanga municipality (Brazilian Southeast region); $b$ : Greater São Paulo metropolitan area (Brazilian Southeast region); $c$ : state of Paraná (Brazilian South region); $d$ : state of Ceará (Brazilian Northeast region); $e$ : Peru; CI: confidence interval $(\alpha=0.05)$. migonei populations of the Brazilian South and Southeast regions, but it is absent from $\mathrm{Mg}$. rabelloi and in the Brazilian Northeastern and Peruvian $\mathrm{Mg}$. migonei populations as well as from the male from Venezuela and the female from Amapá.

\section{TAXONOMIC DISCUSSION}

The characteristics described above allow us to include this new species in the subgenus Migonemyia, in accordance with Galati (1995). With the description of this new taxon this subgenus is seen to consist of three closely related species.

It may be seen in Table I that the average length of the ejaculatory pump of $M g$. vaniae sp. nov. is much greater than those of the other two species, with its confidence interval presenting a small overlap with that of $M g$. rabelloi; however, the duct/pump ratio of this latter species is considerably smaller than that of $M g$. vaniae, sp. nov. and those of the six populations of $\mathrm{Mg}$. migone studied. The length of the ejaculatory pump and the value of the duct/pump ratio of the population of the Northeast region were consistently smaller than those of the other populations observed. Although the average of the Peruvian population was also smaller than those of the populations of the Brazilian Southeast and South there was a small overlap of the confidence intervals of the Peruvian, Iporanga, and state of Paraná populations regarding the duct/pump ratio.

The specimens of the state of Ceará (Brazilian Northeast region) mounted in Canada balsam and NC resins showed some small differences; though these were not significant as their confidence intervals presented considerable overlapping (Table I).

$M g$. rabelloi also presents a larger significant number of setae in the gonocoxite tuft than in that of $M g$. vaniae sp. nov. or those of the $\mathrm{Mg}$. migonei populations (Table II). The populations of $\mathrm{Mg}$. migonei of the Southeastern and Southern regions show an average number close to 6.0 , while in the Northeastern region it is 
4.6 and thus smaller than those in other Brazilian populations, but the smallest average was observed in the Peruvian population (2.6), in some cases there being no setae at all. In a single Venezuelan specimen observed there were 3 ; this number had also been represented in a drawing of a Trinidad specimen (Young 1979). Thus it is possible that in the evolutionary process of the subgenus the number of setae may have increased as in $M g$. vaniae sp. nov. and especially in $\mathrm{Mg}$. rabelloi, and reduced to the point of total loss in the Peruvian population. This point of view is supported by phylogenetic analysis that shows Migonemyia as being closely related to Lutzomyia, this latter frequently having two of its subgenera: Castromyia and Lutzomyia s. str., with 4-6 setae in the gonocoxite tuft (Galati 2003b).
Apart from these differences, another polymorphic characteristic that was observed in the Mg. migonei populations relates to the presence or absence of the papilla on the 5th antennomere (AV). All the specimens observed from the Brazilian South and Southeast regions present the papilla on AV, differently from the populations of the Brazilian Northeast region, Peru, and the only Venezuelan specimen examined, from which it is absent. This papilla is also absent on $\mathrm{AV}$ of $\mathrm{Mg}$. rabelloi.

Beyond these characteristics, the male of $\mathrm{Mg}$. vaniae sp. nov. presents more highly pigmented abdominal tergites with the tergal papillae being more easily observed than those of the other two species. The basal part of the ejaculatory ducts is also more heavily pigmented than in $M g$. migonei or Mg. rabelloi and the paramere is digi-
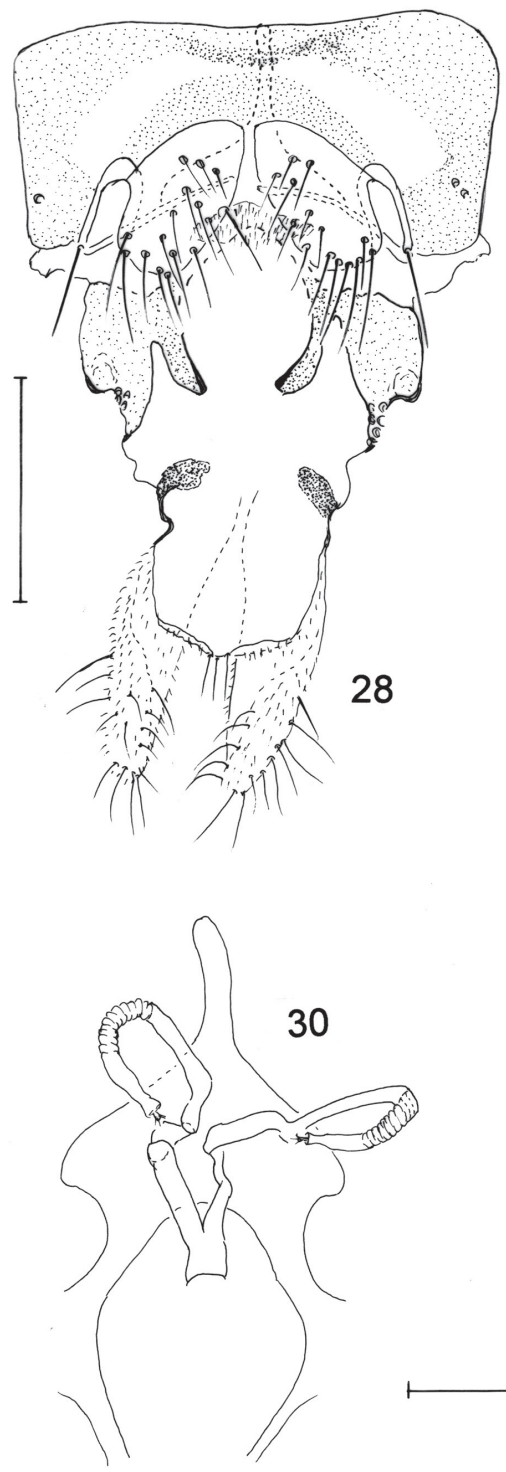

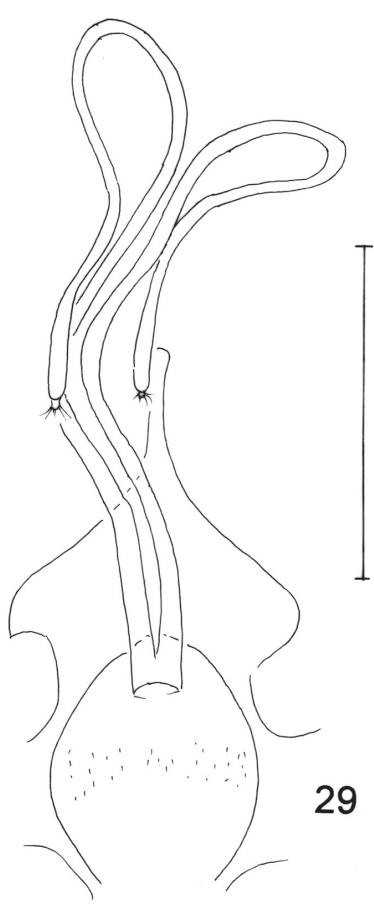

31

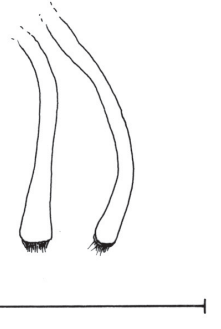

32

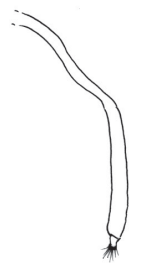

Figs 28, 31: Migonemyia vaniae sp. nov. 28: terminalia, frontal view (allotype female); 31: spermathecae (paratype); 29, 32: $M g$. migonei (female); 29: genital fork and spermathecae; 32: spermathecae; 30: $\mathrm{Mg}$. rabelloi (female) genital fork and spermathecae. Bar $=100 \mu \mathrm{m}$. 


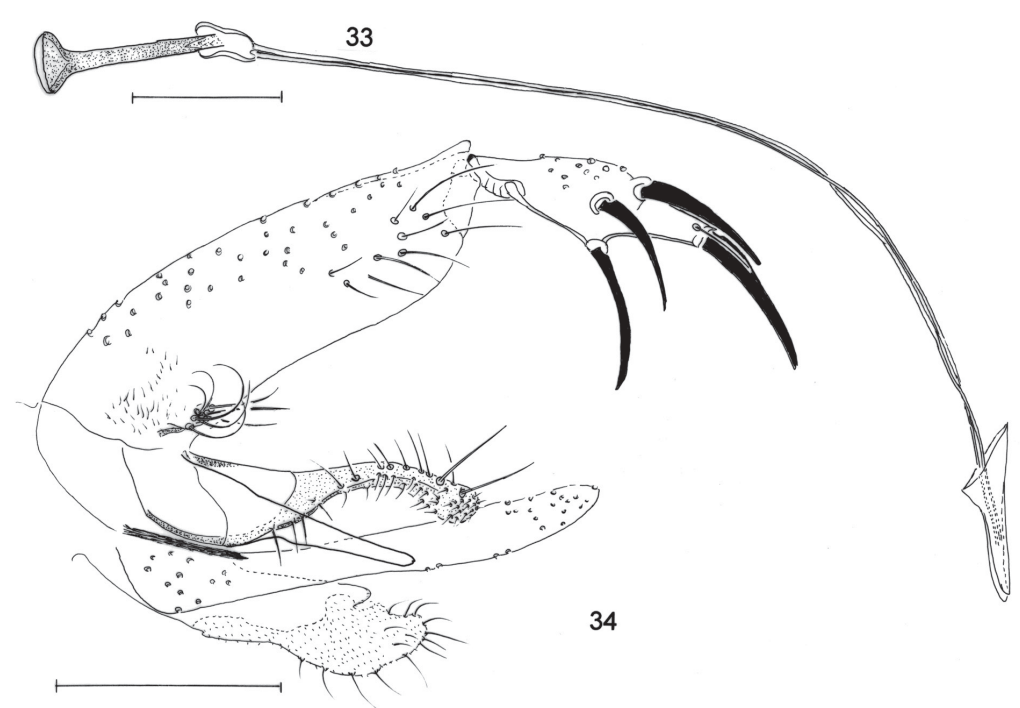

Figs 33, 34: Migonemyia vaniae sp. nov. (holotype male). 33: aedeagus, genital pump, and ducts; 34: genitalia. Bar $=100 \mu \mathrm{m}$.

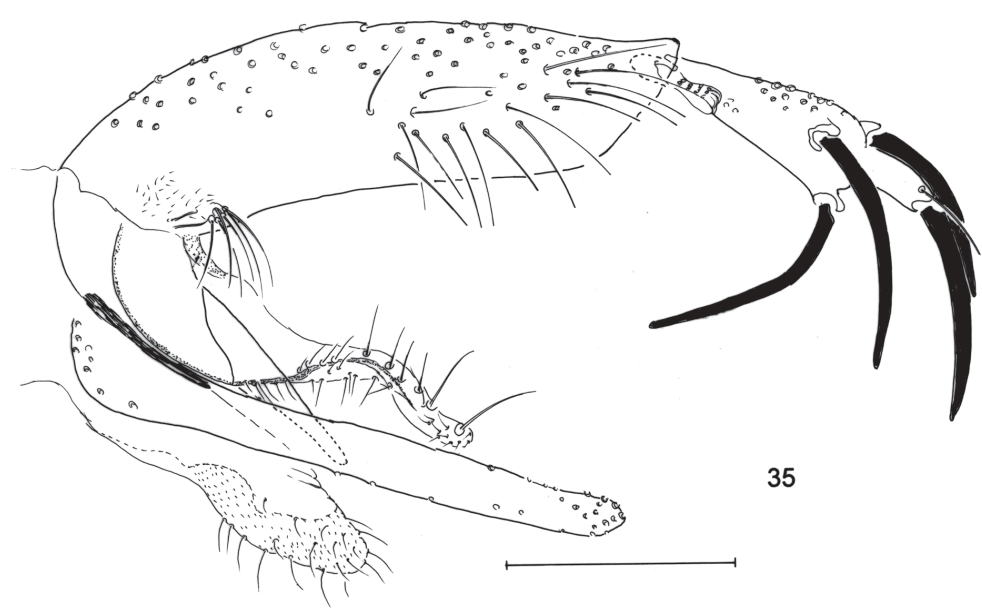

Fig. 35: Migonemyia migonei (male), genitalia. Bar $=100 \mu \mathrm{m}$.

tiform and has a slightly convex dorsal margin (Fig. 34), reminiscent of that of $M g$. rabelloi (Fig. 36) but different from that of $\mathrm{Mg}$. migonei, whose margin presents a strong convexity between two concavities (Fig. 35).

The females of $\mathrm{Mg}$. vaniae sp. nov. and $\mathrm{Mg}$. migone differ from those of $M g$. rabelloi in that the two former species present longer, smooth individual sperm ducts (Figs 26, 29), whereas the latter presents segmentation close to the junction with the spermathecae (Fig. 30). $M g$. vaniae sp. nov. may also be distinguished from $M g$. migonei by its wider spermathecae and the sessile terminal knob (Figs 31, 32). However, this difference is not always very conspicuous.
As regards the variation in the number of setae on the tergite VIII of the females (Table III), Mg. vaniae sp. nov. (of which the range observed varied from 0 to 2 ) and $M g$. rabelloi (0 - 4) differ significantly from that of all the populations of $M g$. migonei $(5-22)$ with the respective averages being $1.0,3.2$ and $\geq 8.7$. In a single specimen observed from the Brazilian North region the numbers are 13 and 15 . Thus the clearly smaller number of setae on the tergite VIII differentiates $M g$. vaniae sp. nov. from $\mathrm{Mg}$. migonei.

The presence or absence of the papilla on AV in the female $M g$. migonei population studied shows the same tendency as in the males. Thus, for the populations of 


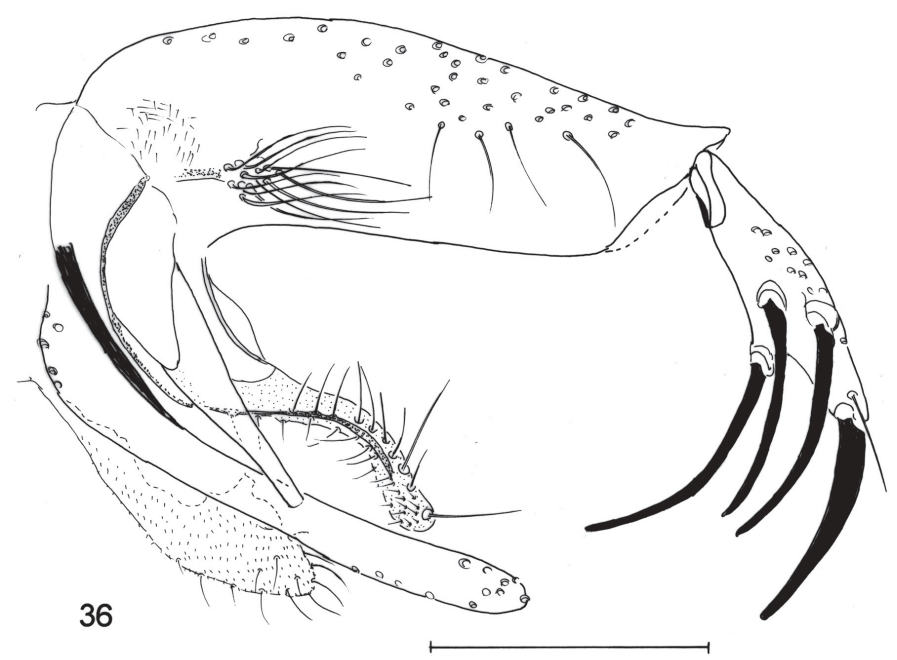

Fig. 36: Migonemyia rabelloi (male), genitalia. Bar $=100 \mu \mathrm{m}$.

the Brazilian Southeast and South regions it is impossible to distinguish $M g$. vaniae from $M g$. migonei, but it is possible to differentiate them from $\mathrm{Mg}$. rabelloi, from which the papilla is absent.

By the above male and female characteristics analyzed, the population of Mg. migonei of Brazilian Northeastern region seems to distinguish of those of Southeast and South regions, however more studies are necessary to determine whether these differences constitute an intraspecific or interspecific variations.

An identification key for the males and females of the three species is presented below to make it easer to distinguish them.

\section{MALES}

1. Gonocoxite with basal tuft consisting of 11-15 setae (Fig. 36); ejaculatory ducts $\leq 2.9$ times longer than the pump . Mg. rabelloi

Gonocoxite with basal tuft of 0-10 setae; ejaculatory ducts $\geq 3.6$ times the lengt...

2(1) Paramere digitiform and slightly convex on the dorsal margin (Fig. 34); ejaculatory ducts and ejaculatory pump measuring respectively $\geq 640 \mathrm{~mm}$ and 146 $\mathrm{mm}$. $M g$. vaniae $\mathrm{sp}$. nov.

Paramere strongly convex on the dorsal margin between two concavities (Fig. 35); ejaculatory ducts and ejaculatory pump measuring respectively $\leq 590 \mathrm{~mm}$ and $130 \mathrm{~mm}$

Mg. migonei

\section{FEMALES}

1. Set consisting of the common and individual sperm ducts and spermatheca relatively short, equivalent to the height genital fork; individual sperm ducts striated in the transitional region with the spermatheca (Fig. 30) Mg. rabelloi
Set consisting of the common and individual sperm ducts and spermatheca very long, measuring two or more times the height of the genital fork; individual sperm ducts smooth in the transitional region with the spermatheca (Figs 26, 29)

\section{...2}

2(1) Tergite VIII with the number of setae varying from 0-2 (Fig. 28); sessile terminal knob (Fig. 31) Mg. vaniae sp. nov.

Tergite VIII with the number of setae varying from 522; pedunculate terminal knob (Fig. 32) .....Mg. migonei

\section{ACKNOWLEDGEMENTS}

To Mr Antônio Gurgel, the owner of the property where the species were collected, and Mr Jânio Ribeiro de Andrade, the local tourist guide, for their cooperation.

\section{REFERENCES}

Aguiar GM, Medeiros VM 2003. Distribuição regional e habitats das espécies de flebotomíneos do Brasil. In EF Rangel, R Lainson, Flebotomíneos do Brasil, Fiocruz, Rio de Janeiro, p. 207-255.

Barreto M, Burbano ME, Barreto P 2006. Registros de Lutzomyia (Diptera: Psychodidae) em nuevas localidades de Colombia. Col Med 37: 39-45.

Barretto MP 1947. Catálogo dos flebótomos americanos. Arq Zool S Paulo 5: 177-242.

Barretto MP 1955. Sobre a sistemática da subfamília Phlebotominae Rondani (Diptera: Psychodidae). Rev Brasil Ent 3: 173-190.

Barretto MP 1962. Novos subgêneros de Lutzomyia França, 1924 (Diptera, Psychodidae, subfamília Phlebotominae). Rev Inst Med Trop São Paulo 4: 91-100.

Cáceres AG, Galati EAB, Pinto J, Paredes R, Réategui R, Pérez J, Chevarria L, Yánez H, Zorrila V 2000. Psychodidae (Diptera) del Peru I. Phlebotominae en Huánuco, Pasco y 
Cusco, su relación com la enfermedad de Carrión y la leishmaniosis tegumentaria. Rev Per Biol 7: 27-43.

Cerqueira NL 1943. Novo meio para a montagem de pequenos insetos em lâminas. Mem Inst Oswaldo Cruz 39: 37-41.

Cipa Group 1997. Computer-aided identification of phlebotomine sandflies of America. Cipa-DB. http://cipa.snv.jussieu.fr (5/ 02/2007)

Dyar HG 1929. The present knowledge of the American species of Phlebotomus Rondani (Diptera, Psychodidae). Am J Hyg 10: $112-124$.

Dyar HG, Nuñez-Tovar M 1926. Notes on biting flies from Venezuela. Insc Meenst 14: 152-155.

Forattini OP 1971. Sôbre a classificação da subfamília Phlebotominae nas Américas (Diptera, Psychodidae). Pap Avul Zool 24: 93-111.

Forattini OP 1973. Entomologia Médica. Psychodidae. Phlebotominae. Leishmanioses. Bartonelose, Edgard BlücherEDUSP, São Paulo, 658 pp.

França C 1920. Observacions sur le genre Phlebotomus. II. Phlébotomes du Brésil et du Paraguay. Bull Soc Port Sci Nat 8: 215-236.

Galati EAB 1995. Phylogenetic systematics of Phlebotominae (Diptera, Psychodidae) with emphasis on American groups. Bol Dir Malariol Saneam Amb 35 (Supl. 1): 133-142.

Galati EAB 2003a. Classificação de Phlebotominae. In EF Rangel, R Lainson, Flebotomíneos do Brasil, Fiocruz, Rio de Janeiro, p. 23-51.

Galati EAB 2003b. Morfologia, terminologia de adultos e identificação dos táxons da América. In EF Rangel, R Lainson, Flebotomíneos do Brasil, Fiocruz, Rio de Janeiro, p. 53-175.

Galati EAB, Gomes AC 1992. Descrição de Lutzomyia rabelloi, sp. n. (Diptera, Psychodidae, Phlebotominae) da região do Vale do Ribeira, Estado de São Paulo, Brasil. Rev Bras Entomol 36: 457-463.

Gil LHS, Basano SA, Souza AA, Silva MGS, Barata I, Ishikawa EA, Camargo LMA, Shaw JJ 2003. Recent observations on the sand fly (Diptera: Psychodidae) fauna on the state of Rondônia, western Amazônia, Brazil: the importance of Psychodopygus davisi as a vector of zoonotic cutaneous leishmaniasis. Mem Inst Oswaldo Cruz 98: 751-755.
Martins AV, Williams P, Falcão AL 1978. American Sand Flies, Academia Brasileira de Ciências, Rio de Janeiro, 195 pp.

Natal D, Marucci D, Reis IM, Galati EAB 1991. Modificação da armadilha CDC com testes para coletas de flebotomíneos (Diptera). Rev Bras Entomol 35: 697-700.

Rohlf FJ, Sokal RR 1981. Statistical Tables, Freemann and Co., New York, p. 148-153.

Saraiva L, Lopes JS, Oliveira GBM, Batista FS, Falcão AL, Andrade-Filho JD 2006. Estudo dos flebotomíneos (Diptera: Psychodidae) em área de leishmaniose tegumentar americana nos municípios do Alto Caparaó e Caparaó, estado de Minas Gerais. Rev Soc Bras Med Trop 39: 56-63.

Salomón OD, Rossi GC, Cousiño B, Spinelli GR, Rojas de Arias A, López del Puerto DG Ortiz AJ 2003. Phlebotominae sand flies in Paraguay. Abundance distribution in the Southeastern region. Mem Inst Oswaldo Cruz 98: 185-190.

Sokal RR, Rohlf FJ 1981. Biometry. The Principles and Practices of Statistics in Biology Research, Freemann and Co., New York, p. 179-270.

Theodor O 1932. On the structure of the buccal cavity, pharynx and spermathecae in South American Phlebotomus. Bull Entomol Res 23: 17-23.

Theodor O 1948. Classification of the Old World species of the subfamily Phlebotominae (Diptera, Psychodidae). Bull Ent Res 39: 85-115.

Theodor O 1965. On the classification of the American Phlebotominae. J Med Entomol 2: 171-197.

Veloso HP, Rangel-Filho AL, Lima JCA 1991. Classificação da Vegetação Brasileira, Adaptada a um Sistema Universal, Departamento de Recursos Naturais e Estudos Ambientais, IBGE, Rio de Janeiro, 124 pp.

Ximenes MFN, Castellón EG, Souza MF, Freitas R, Pearson RD, Wilson ME, Jerônimo SMB 2000. Distribution of Phlebotomine sand flies (Diptera: Psychodidae) in the state of Rio Grande do Norte, Brazil. J Med Entomol 31: 162-169.

Young DG 1979. A Review of the Bloodsucking Psychodid Flies of Colombia (Diptera: Phlebotominae and Sycoracinae), University of Florida, Gainesville, 266 pp.

Young DG, Duncan MA 1994. Guide to the identification and geographic distribution of Lutzomyia sand flies in Mexico, the West Indies, Central and South America (Diptera: Psychodidae). Mem Amer Entomol Inst 54: 1-881. 
